\title{
Mineralocorticoid receptor antagonists: emerging roles in cardiovascular medicine
}

This article was published in the following Dove Press journal:

Integrated Blood Pressure Control

3 October 2013

Number of times this article has been viewed

\section{John W Funder}

Prince Henry's Institute, Clayton, Victoria, Australia

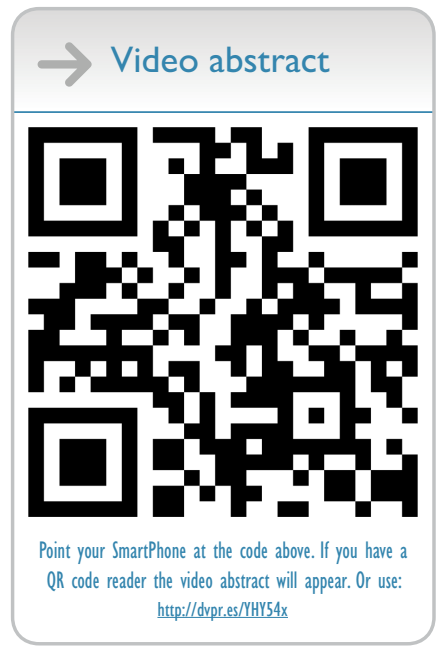

Correspondence: John W Funder Prince Henry's Institute, PO Box 5I52, Clayton, Victoria 3168, Australia Tel +61395943557

Fax +6I39594 6I25

Email john.funder@princehenrys.org
Abstract: Spironolactone was first developed over 50 years ago as a potent mineralocorticoid receptor (MR) antagonist with undesirable side effects; it was followed a decade ago by eplerenone, which is less potent but much more MR-specific. From a marginal role as a potassium-sparing diuretic, spironolactone was shown to be an extraordinarily effective adjunctive agent in the treatment of progressive heart failure, as was eplerenone in subsequent heart failure trials. Neither acts as an aldosterone antagonist in the heart as the cardiac MR are occupied by cortisol, which becomes an aldosterone mimic in conditions of tissue damage. The accepted term "MR antagonist", (as opposed to "aldosterone antagonist" or, worse, "aldosterone blocker"), should be retained, despite the demonstration that they act not to deny agonist access but as inverse agonists. The prevalence of primary aldosteronism is now recognized as accounting for about $10 \%$ of hypertension, with recent evidence suggesting that this figure may be considerably higher: in over two thirds of cases of primary aldosteronism therapy including MR antagonists is standard of care. MR antagonists are safe and vasoprotective in uncomplicated essential hypertension, even in diabetics, and at low doses they also specifically lower blood pressure in patients with so-called resistant hypertension. Nowhere are more than $1 \%$ of patients with primary aldosteronism ever diagnosed and specifically treated. Given the higher risk profile in patients with primary aldosteronism than that of age, sex, and blood pressure matched essential hypertension, on public health grounds alone the guidelines for first-line treatment of all hypertension should mandate inclusion of a low-dose MR antagonist.

Keywords: spironolactone, eplerenone, primary aldosteronism, public health, inverse agonists

\section{Introduction}

The salt-retaining hormone aldosterone was first isolated and characterized in $1953,{ }^{1}$ and in the following year Jerome Conn ${ }^{2}$ reported the successful removal of an adenomatous adrenal gland from a patient with hypertension and hyperkalemia. With the development of tedious but accurate methods for measuring aldosterone the (patho)physiology of the hormone was explored, and it then seemed appropriate to develop an antagonist, given the known effects of aldosterone on sodium retention, and the importance of sodium restriction in some then current cardiovascular treatment regimens, eg, eating boiled rice and dried apricots. The search for an antagonist was then started by G D Searle, in their Skokie laboratories outside Chicago. The assay developed by the lead investigator, now known eponymously as the Kagawa assay, used adrenalectomized rats maintained overnight on normal saline solution without food and injected next morning with aldosterone alone or with candidate antagonist molecules. ${ }^{3}$ The urinary 
$\mathrm{Na}^{+} / \mathrm{K}^{+}$ratio in the aldosterone-injected rats was compared with that in sham-injected adrenalectomized controls, and the ability of a putative antagonist to reverse the effect of aldosterone could then be computed from its effect on the urinary $\mathrm{Na}^{+} / \mathrm{K}^{+}$ratio.

\section{Spironolactone}

The early studies were done in the late 1950s, and the first antagonist, spironolactone, was introduced in 1960. Over 50 years later, this drug remains in widespread use. Spironolactone is a progesterone derivative, sharing with progesterone a high degree of plasma binding, but reduced affinity for progesterone receptors, although it may still show progestin-like side effects, eg, mastodynia and disturbance of the menstrual cycle in women. It has active metabolites, one of which (canrenone) is marketed in Europe as having fewer side effects than its parent compound; another is potassium canrenoate, the water-soluble, injectable form of canrenone.

Spironolactone is categorized as a potassium-sparing diuretic, and for 40 years its use has been essentially confined to states of aldosterone excess in primary and secondary aldosteronism. In times gone by, primary aldosteronism was considered to be a relatively benign form of hypertension, requiring hypokalemia as a sine qua non for diagnosis, and to be relatively rare (accounting for less than $1 \%$ of hypertension), all of which we now know is not the case. Secondary aldosteronism, as in ascites, reflects the combination of a lower metabolic clearance rate of aldosterone (normally aldosterone is cleared by first pass through the liver, so that its metabolic clearance rate is about $1100 \mathrm{~L} /$ day, equivalent to hepatic blood flow), plus the stimulus to aldosterone secretion by a reduction in circulating volume in response to diuretics.

As noted above, spironolactone is not a selective antagonist for aldosterone, because it retains some progestational activity that may be clinically manifest in women. In men, the side effects appear to be estrogenic, but in fact reflect its antiandrogenic activity. These side effects are doserelated, and include gynecomastia, erectile dysfunction, and possibly decreased libido. A potential adverse consequence of spironolactone and of subsequent antagonists, rather than a side effect, is that of hyperkalemia. This is not an issue in patients with normal renal function, unless very high doses are used, which, as noted below, they need not be. In patients with impaired renal function, spironolactone and its congeners should be used with caution, and with regular determination of plasma potassium concentrations.

\section{Mineralocorticoid receptors}

In humans, MR are members of a 48-strong family of nuclear receptors, and share considerable sequence homology with glucocorticoid, progesterone, and androgen receptors. The side effects of spironolactone are thus consistent with the relatively high homology in the ligand binding domain of mineralocorticoid, glucocorticoid, progesterone, and androgen receptors. Spironolactone also has modest affinity for glucocorticoid receptors, but minimal effects, reflecting high circulating levels of glucocorticoid hormones. As the term nuclear receptor suggests, many but not all of the effects of ligand complexed with the receptor reflect DNA-directed, RNA-mediated synthesis of effector proteins. Increasingly, rapid nongenomic effects via MR have been demonstrated in vitro, ${ }^{4}$ and effects via the high-affinity aldosterone-binding membrane protein, GPR-30. ${ }^{5}$ However, the pathophysiologic role of the rapid effects of aldosterone remain only lightly explored.

\section{MR: nonselective but high affinity}

The remarkable feature of MR, which are highly conserved between species, is that they have essentially equivalent (with very high $\mathrm{K}_{\mathrm{d}}$ in the picomolar range) affinity not just for aldosterone, as might be anticipated given its very low (picomolar) plasma concentrations, but also for a range of other steroids. Deoxycorticosterone, which is an MR agonist, circulates at levels equivalent to those of aldosterone, but is overwhelmingly (98\%-99\%) bound to plasma proteins. This makes it only $2.5 \%$ as potent in terms of mineralocorticoid activity in vivo; in addition, its regulation (primarily by adrenocorticotropic hormone) is not appropriate for a physiologic mineralocorticoid, which needs to respond to sodium deficiency, potassium loading, and volume depletion. Perhaps more surprisingly, MR also have affinity for progesterone, cortisol, and corticosterone at a level equivalent to that of aldosterone.

Progesterone is an MR antagonist at the renal level, with high levels during pregnancy driving a 3-10-fold elevation of plasma aldosterone concentrations to maintain sodium homeostasis. While the definition of "antagonist" needs refinement (see below), there is no question of its effect on the principal cells of the kidney. Two features are of interest in terms of the roles of progesterone and MR. First, a single nucleotide mutation in the gene encoding MR, producing an S810L mutant MR, leads to the MR recognizing progesterone as an agonist, leading to juvenile onset hypertension exacerbated by pregnancy. ${ }^{6}$ Second, the high affinity for progesterone appears to be 
tightly conserved among mammalian species, suggesting that hitherto essentially unexplored roles for progesterone as ligand for MR may be physiologically important, in the first instance perhaps in the ovary and/or placenta.

\section{MR: evolutionary considerations}

The relationship between MR and the physiologic glucocorticoids is possibly even more interesting, and certainly more complex. MR were the first of the mineralocorticoid, glucocorticoid, progesterone, and androgen receptor subfamily to branch off the ancestral sequence, in the form of a protein known as the corticoid receptor in lampreys and hagfish. In the lamprey, only 11-deoxycortisol binds with high affinity in the gill cytosol, and upregulates gill $\mathrm{Na}^{+} \mathrm{K}^{+}$-ATPase, consistent with a mineralocorticoid effect via the corticoid receptor. ${ }^{8}$ The MR emerged many millions of years before the aldosterone receptor, which is first found in transition-to-terrestrial vertebrates such as the lungfish, which has both gills and, as the name suggests, lungs. Distinct MR are present in both bony fish (eg, trout and zebrafish) and cartilaginous species (shark and rays), where their "cognate" ligand is probably cortisol. These cartilaginous species also have classical glucocorticoid receptors, with much lower affinity for the physiologic glucocorticoids than for MR. Such MR presumably function as high-affinity glucocorticoid receptors, and the ligands for and physiologic roles of classical glucocorticoid receptors in cartilaginous species remain to be determined.

\section{Epithelial MR: selective activation by aldosterone}

Given this promiscuity of MR in terms of ligands, aldosterone, which circulates at total concentrations about 1000-fold lower than those of cortisol and has free concentrations about 100 -fold lower, faces an uphill battle in terms of activating its receptor in the kidney (and other sodium-transporting epithelia). Over two decades ago, it was proposed that this otherwise overwhelming concentration difference was nullified by high levels of coexpression of the enzyme $11 \beta$ hydroxysteroid dehydrogenase (11ßHSD2), which converts cortisol to receptor-inactive cortisone. ${ }^{9,10}$

Although it is still widely taught that this enzyme operates to allow aldosterone selectivity of MR by denying cortisol MR occupancy, this is not the case. However, two things are certain: under normal circumstances, epithelial MR "protected" by $11 \beta \mathrm{HSD} 2$ are aldosterone-selective in terms of activation; and when 11ßHSD2 activity is compromised, either congenitally in the syndrome of apparent mineralocorticoid excess $^{11}$ or in response to enzyme antagonists, eg, licorice abuse, cortisol acts as an MR agonist in the kidney, producing sodium retention and severe hypertension.

That $11 \beta \mathrm{HSD} 2$ is able to convert cortisol (or corticosterone in rats and mice) sufficiently to reduce its intracellular levels to insignificance is inherently improbable and experimentally not the case. If under normal circumstances cortisol were an MR agonist, 11ßHSD2 would need to convert 999 of every 1000 intracellular cortisol molecules to cortisone to reduce the noise (cortisol) to signal (aldosterone) ratio to $10 \%$. This is not only inherently improbable in an organ that receives $20 \%-25 \%$ of cardiac output, but has been shown not to be the case in studies of adrenalectomized rats. ${ }^{12}$ When rats were injected with tritiated aldosterone, alone or with increasing half-logarithmic doses of nonradioactive aldosterone or corticosterone at doses equivalent to those found in vivo, corticosterone was found to occupy about $90 \%$ of renal and colonic MR, the presence of $11 \beta \mathrm{HSD} 2$ notwithstanding.

If $90 \%$ of renal MR are occupied but not activated by glucocorticoids under normal circumstances, physiologic glucocorticoids are clearly not normally MR agonists. However, when $11 \beta$ HSD2 activity is deficient or absent, they become MR agonists. How can this be the case? The answer lies presumably in the cosubstrate for conversion of cortisol to cortisone-NAD, and its conversion to NADH. Resting levels of NAD vary within the cellular compartments, but a ratio of 600 NAD:1 NADH would not be unexpected in the basal state. When NAD is reduced to $\mathrm{NADH}$, the dynamic range is impressive: for a 100 -fold increase in NADH levels, levels of the cosubstrate NAD fall only marginally from 600 to 500 . In other transcription systems, NADH has been shown to be a potent inhibitor of transcriptional activation, ${ }^{13}$ and presumably a similar phenomenon accounts for glucocorticoid-occupied MR being held transcriptionally inactive by NADH generated by the action of $11 \beta$ HSD2. Therefore, what the enzyme does is two-fold, ie, it debulks intracellular glucocorticoid by $90 \%$ (still leaving a 10-fold higher level than that of aldosterone), and by generating NADH, holds glucocorticoid-occupied MR transcriptionally inactive. At present, this latter effect of NADH has not been demonstrated experimentally, and so rests as Occam's razor rather than cutting-edge science. On the other hand, in the studies detailed below, there is proof that cortisol becomes an MR agonist, mimicking the effects of aldosterone, in the context of tissue damage, reactive oxygen species generation, and the consequent change in intracellular redox state. 


\section{MR antagonists: the renaissance}

Two drivers were responsible for the appreciation of the expanded therapeutic possibilities for MR antagonists. The first was a series of studies done in the early 1990s on the effects of inappropriately high levels of aldosterone (or, less expensively, deoxycorticosterone) on sodium status on the heart and blood vessels in experimental animals. ${ }^{14,15}$ Very early and potentially prismatic studies were done in the 1940s by Hans Selye, but received scant consideration because "everybody knows aldosterone acts on the kidney, not on blood vessels or the heart". When it had been shown conclusively that cardiomyocytes express $\mathrm{MR}^{16}$ and that those in the vessel wall ${ }^{17}$ are 11ßHSD2-protected (ie, physiologic target tissues for aldosterone) the Selye data were suddenly recognized for what they were, and refined and extended in a number of laboratories. It was on the strength of these animal studies that Searle decided to develop epoxymenrenone, (originally synthesized and characterized by Ciba-Geigy) as eplerenone, as a highly selective MR antagonist in animal studies, to complement and perhaps ultimately replace spironolactone.

\section{Eplerenone: a selective MR antagonist}

Eplerenone has only $2 \%-3 \%$ the affinity for MR of spironolactone in vitro, but is much less tightly bound to plasma protein, so has approximately $60 \%$ the potency in vivo. A corollary of the lesser extent of plasma binding is that it is much more rapidly metabolized than spironolactone, primarily by cytochrome P450 3A4 in the liver, so that its half-life is 4-6 hours rather than the approximately 18 hours for spironolactone. Unlike spironolactone, the metabolites of eplerenone are inactive, and its shorter half-life is consistent with the suggestion of a less marked effect in terms of hyperkalemia. Eplerenone has the marked advantage of MR selectivity, so is without sex steroid receptor-mediated side effects; its disadvantages are twofold, ie, price (except in Japan, where it is about one quarter of the global price) and inconsistency in terms of approved indications (eg, heart failure in the US, hypertension in Japan, and post myocardial infarction heart failure in Australia). Although its primary route of metabolism (cytochrome P450 3A4) leaves it open to a range of drug interactions, it appears to be safe, and post-marketing surveys in Japan show that headache is the most commonly reported adverse effect, having been reported in 30 of 30,000 subjects.

\section{Primary aldosteronism}

The second driver was the realization that what we had been taught about primary aldosteronism was not in fact the case, again occurring in the early 1990s. This stemmed in large part from use of the aldosterone to renin ratio as a screening test for the possibility of primary aldosteronism; currently about $10 \%$ of hypertensives are considered to have elevated aldosterone secretion, at least in part autonomous of its major regulators, ie, angiotensin II and potassium concentrations. ${ }^{18}$ On recent evidence, many patients with a high aldosterone to renin ratio but a plasma aldosterone concentration within the accepted "normal range" may well prove also to have primary aldosteronism. ${ }^{19}$ In addition to its prevalence, it is now recognized that about two thirds of patients with primary aldosteronism have bilateral adrenal hyperplasia and about one third have a unilateral aldosterone-producing adenoma.

Hypokalemia is uncommon in patients with bilateral adrenal hyperplasia, being $16 \%$ in the largest study reported to date, ie, the Primary Aldosteronism Prevalence in Italy study, and found in only half of subjects with an aldosteroneproducing adenoma. Finally, rather than the relatively benign elevation of blood pressure previously considered to be the case, primary aldosteronism has been shown to have a much higher cardiovascular risk profile, including for nonfatal myocardial infarction, stroke, and atrial fibrillation, than that in patients with essential hypertension matched for age, gender, and blood pressure. Given that at least two thirds of patients diagnosed with primary aldosteronism are treated medically, spironolactone and eplerenone currently have a much more prominent therapeutic role than just occasional use as potassium-sparing diuretics.

\section{MR antagonists and heart failure Randomized Aldactone Evaluation Study (RALES)}

At the time GD Searle was in the process of developing eplerenone as a selective MR antagonist, it was decided to use spironolactone in a large-scale, international, proof-of-principle study of the effect of MR antagonists in heart failure. This was a courageous decision, because spironolactone was both long out of patent and intended for replacement. RALES (the Randomized Aldactone Evaluation Study) allocated patients with on average New York Heart Association Grade III congestive heart failure to standard of care plus spironolactone (initially $25 \mathrm{mg}$ /day) or plus placebo. The enrollment period was envisaged as three years; halfway through, the trial was halted in light of a marked difference in outcomes between the two groups. Put simply, the addition of $26 \mathrm{mg}$ spironolactone (on average) to standard of care in progressive heart failure reduced mortality by $30 \%$ and hospitalization by $35 \%$, the latter being exciting for normally phlegmatic health economists. 
RALES also provided data on adverse effects. Predictably, despite careful selection in terms of creatinine levels, patients receiving spironolactone showed a higher prevalence of hyperkalemia, which was usually mild and transient. Secondly, and presumably reassuring in terms of the development of an MR-selective replacement, there was a $10 \%$ prevalence of gynecomastia in patients on spironolactone versus $1 \%$ in those on placebo. RALES had an enormous impact in the world of cardiology, elevating aldosterone (wrongly, as it transpires, as explained below) out of the ruck of "neurohumoral factors", but what it should have done was focus attention on the role of MR activation in the progression of congestive cardiac failure. Unfortunately, what it also did was encourage the use of spironolactone in very old patients with heart failure and compromised renal function, with the dose often unregulated and an inevitable spike in hospital admissions with hyperkalemia. ${ }^{20}$ Suboptimal prescribing may also have played a part in such events; in one study, a third of these patients were still being prescribed potassium supplements. ${ }^{21}$

\section{EPHESUS}

Subsequent studies in heart failure using eplerenone understandably did not go head-to-head with spironolactone, but addressed particular subgroups. In EPHESUS (the Eplerenone Post-Acute Myocardial Infarction Heart Failure Efficacy and Survival study), patients with heart failure following myocardial infarction were randomized to receive eplerenone (average dose $43 \mathrm{mg} /$ day, so equivalent to the $26 \mathrm{mg}$ /day of spironolactone in RALES) starting at day 3-8 following admission. Eplerenone or placebo was given in addition to standard of care, and the outcomes in terms of survival and hospitalization were about half those of RALES, ie, improvements of $15 \%-17 \%$. One factor possibly explaining this difference is the improvement in standard of care over the period between the two trials, particularly in the use of $\beta$-blockers; however, a more cogent reason is the difference in mean ejection fraction between trial patients, which was considerably lower in RALES than in EPHESUS. When the subgroup of EPHESUS patients with ejection fractions comparable with those in RALES was examined, the mortality and morbidity results for the two trials were comparable. Two other findings of EPHESUS were that eplerenone was equally effective in diabetic patients, who comprised almost a third of the total, and that the earlier the MR antagonist was introduced, the greater the likelihood of an improved outcome.

\section{EMPHASIS-HF}

The third major trial of MR antagonists in heart failure was EMPHASIS-HF (the Eplerenone in Mild Patients
Hospitalization And Survival Study in Heart Failure) performed in patients with New York Heart Association Class II heart failure. Criteria for inclusion were age $>55$ years, an ejection fraction $<35 \%$, either with an elevated plasma brain natriuretic peptide concentration or within 6 months of hospitalization for heart failure, and a QRS interval > $130 \mathrm{msec}$ if the ejection fraction was $31 \%-35 \%$. The eplerenone dose used was $\leq 50 \mathrm{mg} /$ day, and the primary outcome was death or hospitalization. The trial was stopped after a median followup period of 21 months, with eplerenone showing a $29 \%$ reduction in terms of the primary endpoint, with a four-fold increase in hyperkalemia (plasma potassium concentration $7.2 \%$ versus $1.8 \%$ ). In the words of the Heart Failure Society of America Guidelines Committee, "The efficacy of eplerenone in patients with mild heart failure symptoms translates into a unique opportunity to reduce morbidity and mortality earlier in the course of the disease". ${ }^{22}$

\section{Endocrinology of heart failure}

In addition to the benefit to patients, use of low-dose MR antagonists has proven prismatic in terms of the endocrinology of heart failure. Although patients with heart failure are often characterized as having elevated plasma aldosterone levels, this is not the case unless the patients are either on vigorous diuretic therapy or in rapid decompensation. For example, the patients in the trials cited above all had plasma aldosterone levels in the lower range of normal, together with unremarkable sodium status. Given this situation, despite the use of diuretics, angiotensin-converting enzyme inhibitors, and angiotensin receptor blockers, two questions arise. The first is that of the ligand responsible for activation of cardiac MR, and the second is how spironolactone and eplerenone could be effective at such low doses. It needs to be remembered that $99 \%$ of unprotected cardiac MR are occupied by cortisol, which circulates at plasma concentrations about 100 times those of aldosterone. Secondly, although spironolactone has a relatively high affinity for MR, it is less than that of cortisol/aldosterone.

\section{Experimental equivalence of cortisol and aldosterone in damaged myocardium}

The answer to these questions appears to have come from a basic study of the effect of these steroids on cardiac infarct size using the classical ischemia-reperfusion model. ${ }^{23}$ Aldosterone increases infarct size at low concentrations when added to perfusion fluid; cortisol at similarly low nanomolar doses has an identical effect, blocked by spironolactone but not by the progesterone/glucocorticoid receptor antagonist RU486. 
Glucocorticoids are not normally aldosterone mimics in the heart; when 11ßHSD2 was selectively expressed transgenically in cardiomyocytes, allowing aldosterone to activate a proportion of cardiomyocyte MR, mouse hearts were observed to have both structural (dilated cardiomyopathy) and functional (lowered ejection fraction) deficits. ${ }^{24}$ Taken together, the two studies show that, under normal conditions, physiologic glucocorticoids are MR antagonists in the heart, in that they do not mimic the effect of aldosterone. However, in conditions of tissue damage, as in ischemia-reperfusion, they become MR agonists, so in MR physiologic glucocorticoids are context-dependent bivalent ligands with respect to activation by aldosterone. Therefore, in the failing human heart, myocyte MR are being activated by cortisol in the context of tissue damage, reactive oxygen species generation, and redox charge. Thus, the enigma of the low aldosterone levels in RALES, EPHESUS, and EMPHASIS-HF is explained, and use of the term "aldosterone antagonist" should be expunged from the cardiology lexicon.

\section{MR antagonists are inverse agonists, not "blockers"}

The second question, ie, of the relatively low doses of spironolactone/eplerenone required for substantial effects on mortality and morbidity when added to conventional agents, also appears to be answered by studies using the same ischemia-perfusion experimental model. ${ }^{23,25}$ When spironolactone alone was used as a control in the aldosterone/ cortisol studies cited above, it was noted that it lessened both the area at risk and infarct size, presumably by protecting cells in the infarct margins against apoptosis. It does this at surprisingly low doses, with a maximum effect at $10 \mathrm{nM}$ and a half maximal effect at about $3 \mathrm{nM}$, and has an identical effect in one week adrenalectomized rats, against the formal possibility of residual endogenous corticosteroids. Therefore, it appears to be acting not as a simple "antagonist", denying active steroids access to MR, but as an inverse agonist in concentrations at which only a minority of MR would be spironolactone-bound. Therapeutic concentrations are orders of magnitude higher, even at relatively low doses, so that the effect is seen clinically.

\section{$M R$ and hypertension}

There is currently debate about nomenclature in hypertension. Renal artery stenosis, pheochromocytoma, and primary aldosteronism are referred to as examples of secondary hypertension, in the sense that they are all secondary to a known cause. A case is being mounted to replace "essential" hypertension with "primary" hypertension, in contrast with "secondary" hypertension. "Primary" has overtones of being without cause, which is not tenable, and "essential" is an admission of current ignorance, and is a time-honored problem. Within essential hypertension, various groups can be distinguished, including resistant hypertension (persistent blood pressure elevation despite at least three conventional agents, including a diuretic) and low renin hypertension, each of which accounts for $\geq 20 \%$ of essential hypertension.

\section{Eplerenone and essential hypertension: dose titration studies}

Currently MR antagonists are not considered to be first-line, second-line, or even third-line agents in essential hypertension, and the remainder of this paper attempts to make the case that they be used first-line in all newly presenting hypertensives, for a number of reasons. The first evidence in support of this comes from a retrospective analysis ${ }^{26}$ of two trials of eplerenone as monotherapy in essential hypertension (\#016,\#020, Pharmacia notation) which were not individually published. Crucially, the trials were titration-to-effect (rather than the more commonly found forced-titration) studies in 397 patients of average age 53 years, with mean blood pressure $154 / 99 \mathrm{mmHg}$, mean potassium levels of 4.27 , and normal renin and aldosterone levels. The study was over 12 weeks, after a run-in period, with all subjects started on eplerenone $50 \mathrm{mg} /$ day. At the end of four weeks, about $40 \%$ of patients reached goal (diastolic blood pressure $<90 \mathrm{mmHg}$ ): in retrospect, it is possibly unfortunate that the initial dose chosen was not $25 \mathrm{mg}$. The remaining patients (nonresponders) went onto $100 \mathrm{mg}$ from weeks 5-8, with those who responded to $50 \mathrm{mg}$ remaining on that dose. After four weeks on $100 \mathrm{mg}$, one third of patients reached their target diastolic blood pressure and stayed on that dose; the remaining nonresponders went onto $200 \mathrm{mg}$ /day for weeks 9-12, with half attaining target diastolic blood pressure at this dose, and half being essentially unchanged ( $\Delta$ systolic blood pressure $-2 \mathrm{mmHg}$, diastolic blood pressure $-1 \mathrm{mmHg}$ ).

The study shows a number of things - the (probably) order of magnitude dose differences between patients in terms of their response to MR antagonists, the possibility that in only $20 \%$ of essential hypertensives is MR activation not involved in maintenance of elevated BP, and more. For the purposes of the case to be made here, attention needs to be focused on the change in plasma potassium concentration, which at all three doses was indistinguishable between responders and nonresponders. At none of the three doses was the average increase in plasma potassium concentration more than $0.2 \mathrm{mEq} / \mathrm{L}$; at the highest dose, the $95 \%$ confidence limits were $0.1-0.3 \mathrm{mEq} / \mathrm{L}$. Put simply, the title of the paper makes 
the mechanistic point, "Distinguishing the antihypertensive and electrolyte effects of eplerenone". For the case to be made for use of low-dose MR antagonists in essential hypertension, the message is that, in terms of hyperkalemia, eplerenone when titrated to effect is safe, absent persistent proteinuria (and, obviously, coprescribed potassium supplementation).

\section{Eplerenone: vasoprotection in essential hypertension}

In addition to being safe, MR antagonists are also uniquely vasoprotective in essential hypertension in both diabetics ${ }^{27}$ and in those with normal glucose tolerance. ${ }^{28}$ In the 4E study, eplerenone $200 \mathrm{mg}$ and/or enalapril $10 \mathrm{mg}$ were administered to hypertensive patients for nine months. In terms of the urinary albumin to creatinine ratio as an index of vascular integrity, eplerenone produced a greater reduction than enalapril, and coadministration of the two agents significantly lowered the ratio further. Angiotensin-converting enzyme inhibitors are well recognized to be renally vasoprotective, and MR antagonists appear at least equally efficacious in this regard.

\section{MR antagonists in resistant hypertension}

In addition to being both safe and probably uniquely vasoprotective in essential hypertension, MR antagonists appear to be extremely efficacious in terms of lowering blood pressure in so-called resistant hypertension. Studies using either spironolactone ${ }^{29}$ or eplerenone ${ }^{30}$ have shown major falls in blood pressure (15-30 $\mathrm{mmHg}$ systolic, $10-20 \mathrm{mmHg}$ diastolic) at low doses. While the finding of primary aldosteronism in patients with resistant hypertension is in the order of $20 \%$, such patients respond to MR antagonists no differently from the remainder without elevated aldosterone levels, suggesting that MR activation may be equally important in patients with and without an established diagnosis of primary aldosterone.

\section{MR antagonists and low renin hypertension}

Finally, in a very recent (albeit small) study ${ }^{19}$ comparing patients with an elevated aldosterone to renin ratio and plasma aldosterone at the upper limit of the normal range (designated primary aldosteronism, $\mathrm{n}=24$ ), and a second group of low renin hypertension patients $(n=24)$ with an elevated aldosterone to renin ratio but a plasma aldosterone concentration below the cutoff ( $14.5 \mathrm{ng} / \mathrm{dL})$, striking parallels emerged. The groups were indistinguishable across a range of cardiac, blood pressure, and renal indices, with both improving markedly on low-dose spironolactone (average $29 \mathrm{mg}$ /day at one year). These observations warrant additional studies in low renin hypertension, preferably in comparison with patients matched for age, gender, and blood pressure, and having primary aldosteronism due to bilateral adrenal hyperplasia, which is the commonest cause of autonomous aldosterone secretion. Interestingly, seven of the 24 patients with primary aldosteronism in the study mentioned above had a unilateral aldosterone-producing adenoma, but responded no differently to MR antagonist therapy. What it also suggests is that our current definition of the upper limit of normal for plasma aldosterone concentrations may be too high, with the sort of variation in sensitivity for activation seen across a similar range as that for MR antagonists in the dose-titration study by Levy et al. ${ }^{26}$

\section{Primum non nocere}

A long established guiding principle of medicine is primum non nocere, commonly translated as "first do no harm". In advocating that first-line therapy should include an MR antagonist, it is incumbent upon the advocate to ensure that low-dose MR antagonists are not harmful in patients with uncomplicated essential hypertension. The studies cited here support this interpretation, and in fact point to MR antagonists being both safe and efficacious. For primary aldosteronism, MR antagonists are the drugs of choice in bilateral adrenal hyperplasia, and appear to be reasonably efficacious in aldosterone-producing adenoma, ${ }^{19,31}$ although most practitioners would recommend unilateral laparoscopic adrenalectomy when the patient is willing and able to undergo surgery. So far, so good, but why include MR antagonists in first-line antihypertensive therapy?

\section{Primary aldosteronism: tip of the iceberg}

If the prevalence of primary aldosteronism is $10 \%$ of hypertension, there is no country in the world where more than $1 \%$ of patients with primary aldosteronism are ever screened, let alone appropriately treated. In the US, an annual figure of 11,000 is given for unilateral adrenalectomies performed, ${ }^{32}$ some of these obviously for pheochromocytoma, but perhaps half for aldosterone-producing adenoma. The population of the US is currently 315 million, among whom there are probably 80 million hypertensives, so the estimated number with primary aldosteronism would be about 8 million. If half the adrenalectomies were for aldosterone-producing adenoma, which represents about 35\% of primary aldosteronism, the total number of aldosteroneproducing adenomas plus bilateral adrenal hyperplasias 
treated each year de novo would be in the order of 15,000, ie, one patient in 550 with primary aldosteronism. With an annual population increase of about 2.5 million citizens, of whom approximately 60,000 can be inferred to have/develop primary aldosteronism, the input to the estimated 8 million with primary aldosteronism is more than three times the number of cases treated.

\section{“Normal" aldosterone levels, and the tyranny of cutoffs}

Although studies with stringent cutoff levels might put the population prevalence as lower, ${ }^{33}$ there are indications that the true prevalence of autonomous aldosterone secretion (ie, primary aldosteronism) may in fact be higher than $10 \%$ of hypertensives. When normal levels of aldosterone are defined in normal subjects on free intake and after dexamethasone administration to prevent acute elevation of plasma aldosterone concentrations in response to adrenocorticotropic hormone, a much lower range of normal values is found. ${ }^{34}$ When hypertensive patients undergo a dexamethasone-enhanced fludrocortisone suppression test, over $30 \%$ rather than $10 \%$ show aldosterone values above the $97.5 \%$ level found in normal subjects. This additional $20 \%$ may include patients with low renin hypertension (in a primary aldosteronism/ low renin hypertension study ${ }^{19}$ of 39 consecutive patients with low-renin hypertension, 24 had a positive aldosterone to renin ratio, but fell short of the plasma aldosterone cutoff). These individuals may constitute a fair proportion of the additional $20 \%$, as may patients with resistant hypertension, who similarly may fall under the current cutoff for a "normal" aldosterone level. If the prevalence is truly $30 \%$, then the rate of influx into the primary aldosteronism pool in the US is 10 times the current rate of intervention.

\section{Where do we go from here?}

It is not just a matter of increasing the screening/case detection rate three or ten times to mark time, or more to get ahead. With the cost pressures on health systems worldwide, even doing aldosterone-renin ratios on a million hypertensives per year will cost $\$ 420$ million (the cost of a single test being $\$ 420$ : quoted in 32 ). In most series approximately $20 \%$ of hypertensives have an aldosterone to renin ratio above the cutoff, meaning that they have a $50 \%$ chance of being diagnosed with primary aldosteronism on current criteria. Once these approximately 200,000 patients each year are identified, classically they need to undergo a confirmatory/ exclusion test, reducing the number to a "mere" 100,000 . The guidelines for primary aldosteronism ${ }^{18}$ then stipulate imaging followed by adrenal venous sampling, and unilateral laparoscopic adrenalectomy in the one third of cases that lateralize. The cost would then escalate into many billions if all this could be done, and obviously it cannot. Adrenal venous sampling requires experienced and dedicated interventional radiologists, and it would take essentially a generation to train them. The procedure is expensive, as is laparoscopic surgery. All this is not going to happen in any jurisdiction, and those with occult primary aldosteronism have a far higher risk profile (stroke four-fold, nonfatal myocardial infarct six-fold, atrial fibrillation 12-fold) than that of essential hypertensives matched for age, gender, and blood pressure. ${ }^{35}$

\section{Conclusion}

What to do? Give each person with a positive aldosterone to renin ratio a prescription for an MR antagonist and send them off? The answer proposed is simple: include a low-dose MR antagonist in first-line therapy for all new hypertensives. It is safe, as demonstrated in the study by Levy et al, ${ }^{26}$ as well as vasoprotective in essential hypertension, as shown in the studies by Epstein et al. ${ }^{27,28}$ It is uniquely effective in resistant hypertension, ${ }^{29,30}$ and game-changing in primary aldosteronism. ${ }^{19,31}$ Primary aldosteronism accounts for a substantial and perhaps growing percentage of hypertension, with a heightened risk profile. Currently fewer than one patient in 100 with primary aldosteronism will ever receive properly targeted therapy. As an urgent matter of public policy, the guidelines for "essential hypertension" need to include a low-dose MR antagonist in first-line therapy for all new hypertensives under the age of 70 years, with older patients requiring vigilance in terms of hyperkalemia, despite improvement in microalbuminuria. In addition, an MR antagonist should be included in current antihypertensive therapy for all hypertensives with reasonable renal function and normal plasma potassium levels.

One possible problem is that a number of pharmaceutical companies are seeking to or have developed class $4 \mathrm{MR}$ antagonists, where a class 3 antagonist is nonsteroidal, as selective as eplerenone, and as potent as spironolactone. Class 4 agents are all of the above, plus being renal tubulesparing to allay the concerns voiced about hyperkalemia. If primary aldosteronism turns out to be a much more common cause of hypertension than currently recognized, class 4 agents may in fact be dangerous, in that hypokalemia due to unopposed tubular action of aldosterone is rather more hazardous than hyperkalemia. A second and to date intractable problem is that the endocrinologists write the guidelines for primary aldosteronism, and the (vastly more numerous) cardiologists write those for essential hypertension: we need 
to get together, go over the maths, make an estimate of the public health consequences of inaction, and get it right.

\section{Acknowledgment}

This work was supported by the Victorian Government's Operational Infrastructure Support Program.

\section{Disclosure}

The author reports no conflicts of interest in this work.

\section{References}

1. Simpson SA, Tait JF, Wettstein A, Neher R, Euw JV, Schindler O, Reichstein T. Konstitution des aldosterons, des neuen mineralocorticoids [Constitution of aldosterones, the new mineralocorticoids]. Experientia. 1954;10(3):132-133.

2. Conn JW. Presidential address. I. Painting background. II. Primary aldosteronism, a new clinical syndrome. J Lab Clin Med. 1955;45(1): 3-17.

3. Kagawa CM, Bouska DJ, Anderson ML. Relationship of plasma aldadiene levels and antimineralocorticoid effects of spironolactone in the laboratory. Proc Soc Exp Biol Med. 1964;115:873-840.

4. Funder JW. The nongenomic actions of aldosterone. Endocr Rev. 2005; 26:313-321.

5. Gros R, Ding Q, Sklar L, et al. GPR30 gene expression is required for the mineralocorticoid receptor-independent rapid vascular effects of aldosterone. Hypertension. 2011;57:442-451.

6. Geller D, Farhi A, Pinkerton N, et al. Activating mineralocorticoid receptor mutation in hypertension exacerbated by pregnancy. Science. 2000;289:119-123.

7. Kassahn KS, Ragan MA, Funder JW. Mineralocorticoid receptors: evolutionary and pathophysiological considerations. Endocrinology. 2011;152:1883-1890.

8. Close DA, Yun SS, McCormick SD, Wildbill AJ, Li W. 11-deoxycortisol is a corticosteroid hormone in the lamprey. Proc Natl Acad Sci U SA. 2010;107:13942-13947.

9. Funder JW, Pearce P, Smith R, Smith AI. Mineralocorticoid action: target-tissue specificity is enzyme, not receptor, mediated. Science. 1988;242:583-585.

10. Edwards CR, Stewart PM, Burt D, et al. Localisation of 11 betahydroxysteroid dehydrogenase - tissue specific protector of the mineralocorticoid receptor. Lancet. 1988;2:986-989.

11. Wilson RC, Harbison MD, Krozowski ZS, et al. Several homozygous mutations in the gene for 11 beta-hydroxysteroid dehydrogenase type 2 in patients with apparent mineralocorticoid excess. J Clin Endocrinol Metab. 1995;80:3145-3150.

12. Funder JW, Myles K. Exclusion of corticosterone from epithelial mineralocorticoid receptors is insufficient for selectivity of aldosterone action: in vivo binding studies. Endocrinology. 1996;137:5264-5268.

13. Fjeld C, Birdsong W, Goodman R. Differential binding of NAD+ and NADH allows the transcriptional corepressor carboxyl-terminal binding protein to serve as a metabolic sensor. Proc Natl Acad Sci U SA. 2003; 100:9202-9207.

14. Brilla CG, Weber KT. Mineralocorticoid excess, dietary sodium, and myocardial fibrosis. J Lab Clin Med. 1992;120:893-901.

15. Young M, Fullerton M, Dilley R, Funder J. Mineralocorticoids, hypertension, and cardiac fibrosis. J Clin Invest. 1994;93:2578-2583.

16. Pearce P, Funder JW. High affinity aldosterone binding sites (type 1 receptors) in rat heart. Clin Exp Pharmacol Physiol. 1987;14:859-866.
17. Funder JW, Pearce PT, Smith R, Campbell J. Vascular type I aldosterone binding sites are physiological mineralocorticoid receptors. Endocrinology. 1989;125:2224-2246.

18. Funder JW, Carey RM, Fardella C, et al. Case detection, diagnosis and treatment of patients with primary aldosteronism: an endocrine society clinical practice guideline. J Clin Endocrinol Metab. 2008;93: 3266-3281.

19. Ori Y, Chagnac A, Korzets A, et al. Regression of ventricular hypertrophy in low renin hypertension patients and primary aldosteronism on low dose spironolactone. Nephrol Dialys Transpl. February 1, 2013. [Epub ahead of print.]

20. Juurlink DN, Mamdani MM, Lee DS, et al. Rates of hyperkalemia after publication of the Randomized Aldactone Evaluation Study. $N$ Engl J Med. 2004;351:543-551.

21. Cavallari LH, Fashingraner LA, Bettelshees AL, et al. Racial differences in patients' potassium concentration during spironolactone therapy for heart failure. Pharmacotherapy. 2004;24:265-271.

22. Butler J, Lefrozitz JA, Collins SI, et al. Update on aldosterone antagonists use in heart failure with reduced left ventricular ejection fraction: Heart Failure Society of America Guidelines Committee. J Cardiac Fail. 2012;18:265-281.

23. Mihailidou AS, Loan Le TY, Mardini M, Funder JW. Glucocorticoids activate cardiac mineralocorticoid receptors during experimental myocardial infarction. Hypertension. 2009;54:1306-1312.

24. Qin W, Rudolph A, Bond B, et al. A transgenic model of aldosteronedriven cardiac hypertrophy and heart failure. Circ Res. 2003;93: 69-76.

25. Loan Le TY, Mardini M, Howell VM, Funder JW, Ashton AW, Mihailidou AS. Low dose spironolactone prevents apoptosis repressor with caspase recruitment domain degradation during myocardial infarction. Hypertension. 2012;39:1164-1169.

26. Levy D, Rocha R, Funder JW. Distinguishing the antihypertensive and electrolyte effects of eplerenone. J Clin Endocrinol Metab. 2004;89:2736-2740.

27. Epstein M, Williams GH, Weinberger M, et al. Selective aldosterone blockade with eplerenone reduces albuminuria in patients with type 2 diabetes. Clin J Am Soc Nephrol. 2006;1:940-951.

28. Epstein M. Adding spironolactone to conventional antihypertensives reduces albuminuria in patients with diabetic nephropathy. Nat Clin Pract Nephrol. 2006;2:310-311.

29. Nishizuka M, Zaman R, Calhoun D. Efficiency of low dose spironolactone in subjects with resistant hypertension. Hypertension. 2003; 16:925-930.

30. Calhoun DA, White WB. Effectiveness of selective aldosterone blocker, eplerenone, in patients with resistant hypertension. JAm Soc Hypertens. 2008;2:462-468

31. Catena C, Colussi G, Latenne R, et al. Long-term cardiac effects of adrenalectomy on mineralocorticoid antagonists in patients with primary aldosteronism. Hypertension. 2007;50:911-918.

32. Kaplan N. Primary aldosteronism: evidence a second epidemic J Hypertens. 2012;30:1899-1902.

33. Hannemann A, Wollaschofski H. Prevalence of primary aldosteronism in patients' cohorts and in population-based studies - a review of the current literature. Horm Metab Res. 2012;44:157-162.

34. Gouli A, Kaltsas G, Tzonou A, et al. High prevalence of autonomous aldosterone secretion among patients with essential hypertension. Eur J Clin Invest. 2011;41:1127-1136.

35. Milliez P, Girerd X, Plouin PF, Blacher J, Safar ME, Mourad JJ. Evidence for an increased rate of cardiovascular events in patients with primary aldosteronism. J Am Coll Cardiol. 2005;45:1243-1248. 
Integrated Blood Pressure Control

Dovepress

\section{Publish your work in this journal}

Integrated Blood Pressure Control is an international, peer-reviewed open-access journal focusing on the integrated approach to managing hypertension and risk reduction. Treating the patient and comorbidities together with diet and lifestyle modification and optimizing healthcare resources through a multidisciplinary team approach constitute key

features of the journal. This journal is indexed on American Chemical Society's Chemical Abstracts Service (CAS). The manuscript management system is completely online and includes a very quick and fair peerreview system, which is all easy to use. Visit http://www.dovepress.com/ testimonials.php to read real quotes from published authors.

Submit your manuscript here: http://www.dovepress.com/integrated-blood-pressure-control-journal 